\title{
EN TORNO AL MÉTODO TEOLÓGICO «VER-JUZGAR-ACTUAR»
}

DOI: https://doi.org/10.52039/seminarios.v62i217.127

ROMÁN SÁNCHEZ CHAMOSO*

El modesto objetivo de este trabajo no es otro que llamar la atención sobre algunos aspectos de un tema muy presente en la metodología teológica postconciliar.

\section{Algunos RAsgos que SE DEBEn RESALtAR}

Debido al método, la teología es sistemática, estructurada, capaz de aportar claridad lógica sobre los datos que se revelan en la Escritura. El método, en cuanto tal, como su etimología indica (meta-odos) es un camino o medio necesario para llegar a una meta; en eso precisamente radica su importancia, en ser medio para un fin. Pero esa característica, a primera vista modesta, le confiere toda su importancia: sin camino no es posible llegar a la meta. «En el sentido más restringido de la palabra, se indica con método un procedimiento de investigación ordenado, repetible y auto-corregible, de tal manera que haga posible la obtención de resultados válidos»1.

Todo método es eminentemente formal, no se refiere a los contenidos de una ciencia, sino al procedimiento que debe regir esa ciencia. Al igual que todo saber humano, la teología necesita un método: ya se trate de la teología bíblica, que aporta los materiales para la construcción, o de la teología histórica, que lima y sistematiza los materiales para levantar el edificio, o de la teología práctica, que determina cómo debe vivirse dentro de ese edificio. El método teológico se concentra en resolver la tensión fundamental entre la instancia de la razón y la de la fe².

* Sacerdote Operario Diocesano. Profesor de Teología en el Seminario Jesús Buen Pastor de Ciudad Bolívar, Venezuela.

1. M. Semenaro, El método desde la perspectiva filosófica, en W. Brugger, Diccionario de Filosofía, Herder, Barcelona 1983, 365-367; N. Abbagnano, Diccionario de Filosofía, FCE, México 1961, 810; J. Ferrater Mora, Diccionario de Filosofía III, Ariel, Barcelona 1944, 2400s.

2. Desde el punto de vista teológico, la cita anterior de M. Semenaro; R. Fisichella, Método, en R. Latourelle - R. Fisichella - S. Pié-Ninot, Diccionario de Teología Fundamental, 


\section{a) Método «ver-juzgar-actuar»: Historia}

Hay acuerdo en señalar a Joseph Cardijn (1882-1967) como padre del método «ver-juzgar-actuar» tal como nos ha llegado a nosotros ${ }^{3}$. A este respecto, obras suyas de referencia son: Laicos en primera línea y Jeune-Joc: Methode et organization ${ }^{4}$. Desde el comienzo del método ver-juzgar-actuar, "Cardijn estaba ya seguro de que la acción cotidiana de sus jóvenes obreros promovería una sacudida redentora, indómita, un tanto salvaje y loca, que desafiaría la lógica de las fuerzas dominantes» ${ }^{5}$. Hay un texto inédito de 1958, cuando Cardijn tenía 76 años, que aporta interesantes detalles sobre este proyecto ${ }^{6}$.

Es esencial destacar la relación de Cardijn con la J.O.C. El método consistía en la revisión de vida alentada por Cardijn, en los años 30 del siglo XX. Método que pronto asumió la Acción Católica. Se pretende la acción transformadora de los cristianos en sus ambientes; se intentaba superar el divorcio fe-vida, y era además una propuesta de espiritualidad como corazón de la pastoral7. Hay que destacar que con todo esto los movimientos de renovación pasan a los laicos en la Iglesia ${ }^{8}$.

Entre los antecedentes inmediatos del método ver-juzgar-actuar que han llegado a nosotros cabe destacar al papa Juan XXIII, que lo oficializó9. Pero hay que señalar el Concilio Vaticano ${ } \mathrm{II}^{10}$, sobre todo la constitución pastoral Gaudium et spes (núm. 11), el decreto sobre los laicos Apostolicam actuositatem (núm. 29) y el Mensaje final del Concilio, donde se propone a los jóvenes la «revisión de vida» (núm. 7). Además, habría que tener en cuenta la postura fundamental adoptada por el decreto Optatam

San Pablo, Madrid 1990, 908-934; R. Fisichella, Introducción a la Teología Fundamental, Verbo Divino, Estella 1993; Z. Alszeghy - M. Flick, ¿Cómo se hace la teología?, San Pablo, Madrid 1976.

3. El propio Cardijn indica que las raíces se hallan en L. Ollé-Laprune, cf. D. Franklin Pilario, A vueltas con el método "ver-juzgar-actuar»: Concilium 364 (2016) 93, nota 1.

4. Respectivamente en Nova Terra, Palencia 1965 y Secrétariat Générale, Paris, 8-11.

5. D. Franklin Pilario, A vueltas con el método «ver-juzgar-actuar», 104.

6. www.cardijn.info/cardijn-proyect/the-first-worker-aporte.

7. Simultáneamente se divulgaba en Bélgica la «Teología del trabajo», de M.-D. Chenu, y la «Teología de las realidades terrestres», de G. Thils. Todos estos aportes ayudan a preparar el Concilio Vaticano II.

8. C. Floristán, Teología práctica. Teoría y praxis de la acción pastoral, S[gueme, Salamanca 2002, 379s.

9. Encíclica Mater et magistra, 217-218. Es la primera vez que se cita explícitamente en un documento del magisterio pontificio. C. Floristán, Ver-juzgar-actuar, en Nuevo Diccionario de Pastoral, Paulinas, Madrid 1990.

10. Para una síntesis del Vaticano II, D. Franklin Pilario, A vueltas con el método «ver-juzgar-actuar», 94-95. Este método «llegó a ser el distintivo del espíritu del Vaticano II» (p. 94). 
totius (núm. 16), en el que se replantea el método teológico, «sancto Thomas magistro», pero sin seguirlo literalmente, sino más bien como actitud intelectual que se debe adoptar ante el saber y la investigación. Todo ello sostenido y animado por la Escritura, que conjuga la orientación científica con la pastoral.

A partir del Concilio Vaticano II, son relevantes enciclopedias como Mysterium salutis (teología global repensada a partir del Vaticano II), cuyas categorías teológicas se asumen y producen un fuerte impacto en el método: «historia», "pluralismo teológico», "diversos modelos de interpretación» a veces opuestos, pero que no son incompatibles en teología católica. Entre estos «modelos» con los que se acuña la teología postconciliar cabe reseñar el «trascendental», el «hermenéutico», el «narrativo», el "salvífico», el "paradigmático», el "práxico», etc.; todos estos modelos acontecen de manera simultánea y todos hacen un aporte específico que hay que valorar; lo que parece descartado es el modelo «clásico» o «neoescolástico».

Hay que observar que en distintas encíclicas sociales recientes el magisterio oficial de la Iglesia recurre en líneas generales a la metodología de ver-juzgar-actuar. Por otra parte, los episcopados de África y Asia intentan adaptarlo a su situación; asimismo, este método es seguido por diversos movimientos apostólicos y asociaciones de apostolado seglar como la Acción Católica, el Movimiento Familiar Cristiano o las Comunidades eclesiales de base.

\section{b) El método se «latinoamericaniza» ${ }^{11}$}

El método ver-juzgar-actuar ofrece un «modelo pragmático» y, por ello, muy cercano a uno de los principales rasgos de la teología de la liberación. Momentos principales del método teológico son el auditus fidei (momento positivo) y el intellectus fidei (momento reflexivo), ambos necesarios para poder hablar de verdadero método teológico. Pero hay otros motores que cultiva la teología de la liberación, a saber: el momento transformativo de la realidad, con el correspondiente compromiso con la fe que se profesa

11. Cf. R. Biord Castillo, Ponderación teológica del método ver-juzgar-actuar: ITER Revista de Teología 34 (2004) 19-52. También R. Oliveras, Historia de la teología de la liberación, en J. Ellacuría - J. Sobrino (eds.), Mysterium liberationis. Conceptos fundamentales de la teología de la liberación I, Trotta, Madrid 1990, 1750. Para una visión de conjunto de este método en la teología de la liberación, puede consultarse la revista Concilium 96 (1974), número monográfico; A. González, Vigencia del método teológico de la teología de la liberación: Revista Latinoamericana de Teología. 
(praxis, «actuar»), y la spes quaerens intellectum, o sea, cómo alimentar la fe en una situación adversa ${ }^{12}$.

Además de los amplios trabajos sobre este tema de distintos teólogos latinoamericanos, resulta significativo acudir a los documentos representativos del propio episcopado latinoamericano, origen de las mediaciones socio-analítico-hermenéuticas y pastorales de la teología de la liberación latinoamericana. En estas Asambleas generales del episcopado latinoamericano, el método ver-juzgar-actuar adquiere carta de naturaleza latinoamericana.

MEDELLín (1968). Es incomprensible sin el Vaticano II y sobre todo sin la constitución pastoral Gaudium et spes (el documento más citado después de la Biblia). El aporte de Medellín fue decisivo al consagrar el método ver-juzgar-actuar y hacerlo entra en la teología por la puerta grande. Se adopta este método, aunque varían los nombres con que se le designa. «Ver» la situación (documentos 2.3.5.6.9.11.16), los hechos (doc. 1.7.10.15), la realidad (doc. 4.8). «Juzgar»: reflexión teológico-pastoral (doc. 1.2.9.11), principios teológicos (doc. 6.7.15), criterios teológico-pastorales (doc. 5.10), presupuestos teológicos (doc. 13), justificación (doc. 16), motivación doctrinal (doc. 14). «Actuar»: recomendaciones pastorales (doc. 4.5.6.7.9.10.16), orientaciones pastorales (doc. 4.11.13.14.15), conclusiones pastorales (doc. 2.8), proyectos pastorales (doc. 1).

PUEBLA (1979). Continúa y reafirma la opción de Medellín. En su documento se destacan los números 29 y 30 . Se centra especialmente en el «actuar»: insiste en las opciones pastorales (6 veces), en las líneas de acción pastoral (2 veces) y en otros temas como orientaciones pastorales, sugerencias pastorales, proyectos pastorales y otros aspectos diversos pastorales. A Puebla se debe la matización: opción «preferencial» por los pobres. Por tanto, Medellín y Puebla dan un paso gigantesco en la metodología teológica. «El magisterio de Medellín, así como el de Puebla, elaboró una reflexión pastoral con el esquema ver-juzgar-actuar, que, aun cuando había sido creado en otro contexto, tomó una significación nueva a la luz de la teología de los signos de los tiempos» ${ }^{13}$.

12. Una fórmula sencilla es la atribuida a G. Gutiérrez: «Cómo mostrar al pobre que Dios lo ama». El método referido a la teología de la liberación aborda el espinoso tema de la «liberación histórica de los oprimidos», que viene a ser una de las marcas distintivas de la teología de la liberación, lo que es más nuevo y más típico de tal teología (C. Boff, Epistemología y método de la teología de la liberación, en Mysterium liberationis I, 79-113).

13. R. Biord Castillo, Criterios para efectuar un discernimiento cristiano de una situación histórica, en XXII Jornadas de Teología y reflexión, marzo 2004. 
SANTO DOMINGO. Se eclipsa el método ver-juzgar-actuar, aunque lo reasume para la pastoral juvenil (documento 1.19). No obstante, esta Asamblea se muestra recelosa ante este método, porque -se decía- ofrece una visión únicamente desde las ciencias humanas; en el trasfondo están las Instrucciones de la Congregación para la Doctrina de la Fe, Libertatis nuntius (1964) y Libertatis conscientia (1987).

APARECIDA. Supone la recuperación del método, una vez disipadas las reservas de Santo Domingo. Recogemos un juicio global sobre la novedad aportada en Latinoamérica de un joven teólogo de esta tierra: «Aunque había sido creado en otro contexto, tomó una significación nueva a la luz de la teología de los signos de los tiempos. El momento del ver constituye la instancia de la atención prestada a la historia como lugar teológico, que permite discernir el significado actual de la revelación y de la fe. Ese discernimiento se hace con el criterio propio del segundo momento, el juzgar, que consiste en iluminar lo que se ha visto a la luz de la palabra revelada, la cual, a la vez que permite comprender mejor la historia, es también mejor comprendida desde el impacto de la historia. Finalmente, explicitada esta revelación, gracias a la historia actual, el magisterio orienta concretamente la respuesta de la fe, hoy y aquí; es el tercer momento, el actuan ${ }^{14}$.

Por tanto, el método adquiere un perfil y una perspectiva propia, determinada por la categoría de los «signos de los tiempos». "La capacidad de ver teológicamente la historia latinoamericana supone ver desde dentro, es decir, desde el compromiso práctico de la acción transformadora» ${ }^{15}$.

El método ver-juzgar-actuar es una de las características de la teología latinoamericana y está inseparablemente ligado a ella. Esta teología transfiere precisamente a dicho método su importancia, ya que «expresa la esencia de la fe cristiana» ${ }^{16}$.

En definitiva, el método ver-juzgar-actuar se ha mostrado muy eficaz como método teológico pastoral, aunque no ha dejado de encontrar resistencias ${ }^{17}$. Resulta plenamente actual: «La intuición fundamental de la

14. Ibid., cita ampliada.

15. Ibid. Coincide además con un teólogo europeo: C. Floristán, Teología práctica. Jon Sobrino aporta su peculiar punto de vista: «latinoamericanizar» el método es superar la exterioridad respecto a América Latina: «Significa no solo compartir la naturaleza o la cultura de los hombres y mujeres del continente, sino, sobre todo, lo que en ellos es débil y necesitado. La inserción entre los pobres, la solidaridad con ellos, la opción por ellos» (El principio-misericordia. Bajar de la cruz a los pueblos crucificados, Sal Terrae, Santander 1992, 208).

16. J. Sobrino, «Presentación», en Mysterium liberationis I, 10.

17. R. Ramírez, Método teológico-pastoral = ver-juzgar. 
teología de la liberación es más relevante que nunca. Ha puesto el dedo en la llaga de la realidad del continente latinoamericano, llaga que sigue ensanchándose y enconándose, porque esta teología no es una moda pasajera, sino que va en aumento con su correlato: la opresión, por lo que resulta necesaria» ${ }^{18}$.

Hay un denominador común en todos los niveles en que se desarrolla la teología de la liberación: una fe transformadora de la historia, una práctica liberadora del amor, la historia concreta a partir del fermento de la fe. La misma savia que corre por las venas del árbol (teología de la liberación profesional) es la que pasa por el tronco (teología de la liberación pastoral) y la que asciende de las raíces secretas (teología de la liberación popular). Así se articulan sorprendentemente estas tres fuentes o niveles del pueblo de Dios (teología, pastores y laicos), todo construido sobre un eje: misión liberadora, que transita el mismo camino (método): ver-juzgar-actuar.

\section{c) Actualización del método teológico}

Después de siglos de vigencia del método deductivo, que gozaba del favor oficial, se recupera con fuerza el método inductivo, que tanta vigencia tuvo en otras épocas eclesiales; baste recordar la gran Escuela de Antioquía en la Antigüedad. Encontramos aquí una de las causas del éxito: el método inductivo parte de la situación concreta y se aleja de los métodos deductivos, los de las grandes ideas universales. Con todo, ambos métodos se complementan.

El método inductivo arranca del análisis de la situación; ella es su punto de partida, y tan variada y múltiple como la mil estatuto de la existencia humana. Pero hay que hacer alguna precisión en relación al estatuto peculiar de la teología: esa situación es leída e interpretada "a la luz del Evangelio» (Gaudium et spes, 4), «a partir del Evangelio» ${ }^{19}$, o sea, a la luz de la revelación (Optatam totius, 16); una situación, en definitiva, que se aborda con visión de $\mathrm{fe}^{20}$ y con visión y corazón de pastores ${ }^{21}$, todo lo cual implica un juicio cristiano, crítico, con «discernimiento espiritual» de la realidad.

Han surgido multitud de imágenes para representar visualmente este método, un exponente de la importancia que se le ha otorgado. La validez teológica de este método está bien contrastada. Vale para la teología en

18. J. Sobrino, «Presentación», 11.

19. Documento de Puebla, 15.

20. Ibid., 14.

21. Ibid., 14. 
cuanto se concibe como reflexión crítica, metódica y sistemática de la fe. En nuestro tiempo, ha contribuido a ampliar notablemente el espacio de la metodología teológica, sobre todo a partir de la consagración recibida por el Vaticano II. El «anclaje en la realidad» es el mayor mérito del método ver-juzgar-actuar.

\section{LOS MOMENTOS O TIEMPOS DEL MÉTODO}

Desde los inicios del método que propuso J. Cardijn, se compone de tres pasos internamente articulados, los cuales se corresponden a tres tiempos de la acción pastoral22. Veámoslo en concreto.

\section{a) Descripción del método}

Ver. Consiste en analizar un hecho de vida con sus causas y consecuencias. El acento se pone en la persona que analiza (no en las ideas o las cosas), se invita a revisar su vida, trabajo, familia, sociedad. Es un análisis social, es lo que hoy llamamos revisión. Ha tenido siempre en cuenta los contextos plurales, culturales, de género y de religión; es una «pluralización» necesaria. El actual sistema de globalización pide una revisión-actualización de este «ver». «El contexto plural se convierte ahora en el nuevo locus theologicus» ${ }^{23}$.

Juzgar. ¿Qué dice Dios sobre la situación analizada? Es el momento central del método en cuanto método teológico. Es la toma de posición del creyente frente al hecho analizado: cómo se ve desde Dios y desde la fe. Se buscan hechos similares en el Evangelio, en la vida de Jesús o en la Biblia en general. Surgen unas consecuencias del encuentro con la Palabra de Dios y una llamada a la conversión. Se trata de un verdadero discernimiento creyente. Es la iluminación teológico-pastoral desde fundamentos bíblicos y magisteriales, que arrojan luz especial sobre la situación; esta iluminación convoca a la conversión según el proyecto de Dios. Hoy vemos más claramente que hay que ampliar esta «audición», de forma que cuenten las voces de la realidad múltiple y heterogénea dentro de la explicación de los principios cristianos; hay que escuchar, ante todo, la voz del Totalmente Otro, pero también la del otro a través del cual Dios nos habla. Hoy se dice que hay que escuchar a la «Iglesia docens» y a la «Iglesia docta», o sea, a

22. Es lo llamado «las tres edades del tiempo» (E. Schillebeeckx).

23. D. Franklin Pilario, A vueltas con el método «ver-juzgar-actuar», 96. 
los fieles, revalorizando el «sensus fidei» ${ }^{24}$, y de modo especial a los «signos de los tiempos» por ser un lugar teológico significativo.

Actuar. ¿Qué debo hacer para mejorar la situación analizada? Es el momento del compromiso, con lo que el principal protagonismo lo asume la persona, Se trata de ver la actitud que debe adoptar la persona en la vida. Hay que individualizar los criterios de juicio que se deben modificar, los hábitos cuestionados por la Palabra de Dios y las acciones pertinentes que se deben emprender.

Tanto el análisis de la situación («ver») como el discernimiento creyente («juzgar») están orientados a la acción que busca transformar la realidad («actuar»); supone, pues, un profundo cambio de la realidad-situación de la que se ha partido, cambio que significa una fuerte resistencia frente al inmovilismo y conformismo de dentro de la Iglesia y a los efectos de factores diversos externos a ella que son adversarios del Evangelio. Con gusto acogemos este reciente testimonio sobre el valor del actuar: «La lectio divina no termina su proceso hasta que llega a la acción (actio) que mueve la vida del creyente a convertirse en don para los demás en la caridad ${ }^{25}$. De esta forma, el don recibido de Dios se convierte en tarea, en compromiso humano; a través de ese don recibido de Dios descubrimos que él toma parte a favor del oprimido y necesitado (Ex 14, 25). «Dios nos exige que acojamos su misericordia y que la compartamos ${ }^{26}$.

Es el momento de dar respuesta pastoral, mediante el trazado de líneas de acción, de orientaciones que hagan operativos los principios. Es el momento de la primacía del compromiso concreto de la praxis frente a cualquier idealismo genérico. Ahora resulta fundamental la planificación. En la teología de la liberación latinoamericana se le da especial relieve a la acción, por cuanto es tomada como punto de partida (práctica de la liberación, praxis personal de liberación) y como punto de llegada (compromiso concreto); no estamos ante un "círculo vicioso», sino ante un "círculo hermenéutico» teológico.

En los teólogos de la liberación, la pragmática prevalece sobre la semántica. La filosofía del lenguaje ha destacado en nuestros días que para comprender algo es mejor analizar sus usos, sus malos usos, sus buenas y malas aplicaciones (Wittgenstein). Un método puede ser bueno, pero se puede usar incorrectamente.

24. Ibid., 98-101.

25. Papa Francisco, carta apostólica Vultum Dei quaerere, 21.

26. M. Legido, Misericordia entrañable. Historia de la salvación anunciada a los pobres, Sígueme, Salamanca 1987, 152. 
Hoy se ve necesario ampliar el espectro del actuar. Esta voz ha resonado en la Iglesia universal, en asambleas diocesanas, en salones parroquiales, en el seno de los movimientos de apostolado. Hay que organizarse para la acción y para el cumplimiento de la misión de otra forma. No se puede planificar de espaldas a la realidad ${ }^{27}$. Hay que replantear el tema del liderazgo ${ }^{28}$. Hay que recuperar el valor de la actividad diaria del creyente, que resiste y sobrevive en un ambiente hostil; es una «resistencia cotidiana». Todo ello supone y necesita un sujeto personal o comunitario creativo, capaz de hacer frente al ambiente dominante no conforme con el Evangelio.

A modo de sencilla síntesis trinitaria de estos momentos del método puede señalarse lo siguiente: ver con los ojos del Padre, juzgar con los criterios del Hijo, actuar bajo el impulso del Espíritu ${ }^{29}$.

\section{b) Soporte filosófico del método}

Se lo debemos fundamentalmente a Ignacio Ellacuría, que se inspira a su vez en su maestro Xabier Zubiri ${ }^{30}$.

Primer momento. «Hacerse cargo de la realidad». Es el momento noéti$c o$, de análisis y conocimiento de la realidad («ver»). Se trata de un conocimiento hondo, serio, profundo. Marcelino Legido ve antecedentes bíblicos en el conocimiento que Yahvé tiene de su pueblo, esclavo en Egipto ${ }^{31}$.

Segundo momento. "Cargar con la realidad». Es el momento ético, momento fundamental porque comporta ver como creyentes la realidad conocida («juzgar»). Significa encarnarse en la realidad de este mundo, dejarse afectar, en actitud solidaria y creyente. De nuevo hallamos un antecedente bíblico ahora en el Siervo de Yahvé ${ }^{32}$. Jesús, tras las huellas del Padre, ama a los oprimidos estando con ellos, no se desentiende de las responsabilidades y, a partir de aquí, viene el compromiso de erradicar el mal. Como la Palabra de Dios, hay que mantener una cercanía absoluta

27. Papa Francisco, Evangelii gaudium, 96 (22 de julio de 2016) (en adelante: EG).

28. R. Sánchez Chamoso, Vocación cristiana y liderazgo. Premio Trípode, Caracas 2003.

29. Así, R. Ramírez, Método teológico-pastoral = ver-juzgar.

30. I. Ellacuría, Hacia una fundamentación filosófica del método teológico latinoamericano: ECA 322/3 (1975)149s.

31. Este amor es «vivir y padecer desde las entrañas. Conocer es comulgar en vida y en amor» (M. Legido, Misericordia entrañable, 116).

32. «Cristianamente no se erradica el pecado desde fuera del mismo, ni solo oponiéndole otro poder a su fuerza destructora. Hay que estar disponible a la posibilidad de cargar con su peso destructivo en sus diversas formas de amenazas, persecución y muerte» (J. Sobrino, El principio-misericordia, 103). 
hasta el final. «Cargar con la realidad» no es simplemente una limosna, en la que el donante da algo de lo que tiene sin por ello comprometerse necesariamente en lo más profundo de su ser personal. No se trata aquí de un «mero dar», o de una «ayuda pastoral», sino de un proceso de solidaridad continuada, así es la verdadera solidaridad ${ }^{33}$.

Tercer momento. «Encargarse de la realidad». Es el momento práxico, que muestra la insuficiencia del juicio teórico-ético para pasar a un compromiso. «El testimonio de la misericordia entrañable de Dios no está sólo en optar por los oprimidos, sino en ponerse a luchar con ellos, ponerse de parte de ellos ${ }^{34}$. Estamos ante la solidaridad efectiva, en el compromiso real con el necesitado; es el «conllevarse mutuamente» de san Pablo (Rm $1,12 \mathrm{~s})$; es la solidaridad tangible en un «dar y recibir» mutuo; es enrolarse en la "construcción histórica» de la comunión ${ }^{35}$. La antropología teológica insiste en la dimensión práxica del ser humano y, por tanto, del creyente, algo necesario para no dejar la realidad abandonada a su miseria, aunque esta dimensión práxica no deberá olvidar nunca la gratuidad.

Es sobradamente conocido cómo la teología latinoamericana se comprende conscientemente a sí misma como intellectus cuya finalidad directa es configurar una praxis, orientándola, animándola, de modo que la teología se convierta en intellectus de una praxis, o sea, supone una invitación a reaccionar ${ }^{36}$. La teología es el momento ideológico de la praxis eclesial e histórica, el elemento consciente y reflejo de una praxis ${ }^{37}$. Si la teología es «intellectus de una praxis», podemos decir que es «intellectus de una misericordia primordial».

En el método «ver-juzgar-actuar» se encierra un potencial humanizador; con este método, la teología hace una «oferta de humanización», al mismo tiempo que ofrece un «potencial evangelizador» ${ }^{38}$. Pero no todo en el Tercer Mundo es así, de hecho son minoría los que se enrolan activamente con los valores descritos, aunque los teólogos latinoamericanos no

33. Más ampliamente en J. Sobrino, El principio-misericordia, 214s.

34. M. Legido, Misericordia entrañable, 124.

35. Sobre la fe personal vivida solidariamente con los otros, J. Sobrino, O. c., 239-245. La fe del otro es importante para la propia fe; cree la persona, pero no cree sola, sino en esencial apertura a los otros en la propia fe; inclusive la antropología viene en ayuda nuestra: ser hombre es ser corresponsable con los hombres.

36. J. Sobrino, El principio-misericordia, 68.

37. I. Ellacuría, «La teología como elemento ideológico de la praxis eclesial», en Estudios Eclesiásticos 207(1978) 457s.

38. Confluencia del potencial evangelizador y del potencial humanizador es uno de los resultados de la Asamblea de Puebla (J. Sobrino, El principio-misericordia, 130), idea certeramente expresada por Pablo VI en «Evangelii nuntiandi»: «evangelizar es humanizar». 
se recatan en afirmar que en el Tercer Mundo es más fácil ser profeta, buen samaritano y testigo de la fe, o sea, «vivir la fe de otra manera» ${ }^{39}$.

\section{c) Epistemología acorde con el método ${ }^{40}$}

Hay una estrecha correlación entre los tres momentos o tiempos fundamentales del método "ver-juzgar-actuar» y una serie de mediaciones que articulan una epistemología típica de la teología de la liberación.

Al ver corresponde la mediación socio-analítica, lograda con el necesario auxilio de las ciencias sociales. Se estudia la realidad de la situación concreta, sus causas y consecuencias con el aporte que proporcionan estas ciencias humanas.

Al juzgar corresponde la mediación hermenéutica. El creyente contempla la situación descrita bajo la autoridad de la Palabra de Dios. Se profundiza en el plan divino en relación con el «ver», o sea, es un «ver a la luz de la fe». Se solicita de la Palabra de Dios la luz e iluminación específicas, con lo que se logra una nueva lectura de la Biblia.

Al actuar corresponde la mediación práxica. Se contempla la situación analizada en el «ver» e iluminada por el «juzgar» desde el lado de la acción del creyente. Se buscan las líneas operativas para enderezar la situación descrita, de forma que encaje en la perspectiva cristiana. Es vivir el compromiso de la fe; es el nexo entre la fe del creyente con la práctica concreta; es, en fin, «la praxis de la caridad», esa fe que obra por el amor (Gal 5, 6).

\section{d) El método se amplía: «evaluar» y "celebrar»}

De alguna forma, el paso que ahora se da había sido previsto. Escribe Clodovis Boff: «La fe no se reduce a la acción, aunque liberadora. Es 'siempre mayor'. La Teología de la liberación lleva también al templo. Y desde el templo, lleva de nuevo al fiel a la plaza pública de la historia, ahora cargado con todas las fuerzas divinas y divinizadoras del misterio del mundo que es Dios» ${ }^{41}$.

De hecho, en su desarrollo histórico, el método ver-juzgar-actuar conoce en la Teología de la liberación momentos adicionales: a) Evaluar, porque la realidad es dinámica, la evolución enriquece y perfecciona, y así sugiere nuevas acciones; es lo que comúnmente llamamos «ponerse

39. J. Sobrino, El principio-misericordia, 131-132.

40. Seguimos a C. Boff, Epistemología y método de la teología de la liberación, nota 15. 41. Ibid., 112. 
al día $»^{42}$. b) Celebrar. Por su naturaleza, todo el proceso creyente lleva a la celebración gratuita y agradecida; la celebración no es un mero adorno estético, sino acción de gracias por la presencia transformadora de Dios en la historia, a la que se suma gustoso el actuar celebrativo creyente.

Estos dos momentos adicionales fueron aportados en el «Primer Congreso Latinoamericano de Jóvenes», de Cochabamba (1991). Al ampliarse así el método: ver-juzgar-actuar-revisar-celebrar, se muestra mejor que antes que una metodología, implica un estilo de vida y una espiritualidad que vive y celebra el descubrimiento de la presencia de Dios en la historia, la actitud de conversión personal continua y el compromiso para la transformación de la realidad.

\section{e) La Teología de la liberación es una teología global}

Se ha lanzado sobre la Teología de la liberación el reproche de que es una teología parcial, regional, sectorial, particular, que no contempla la totalidad y globalidad del misterio cristiano ni la universalidad de la Iglesia. A esta acusación se le ha añadido también la de que no es propiamente teología, sino una reflexión sociológica sobre la fe cristiana. Ambas acusaciones han sido constantemente rebatidas desde el inicio.

En primer lugar, es auténtica teología cristiana por ser una verdadera reflexión del creyente sobre su fe, aunque es un discurso teológico distinto del tradicional ${ }^{43}$. Además, su núcleo indiscutible y aglutinante es el Dios cristiano: el Dios de la Biblia, el Dios de la fe cristiana, el Dios de la Iglesia, el Dios de la gran Tradición, el Dios de la pastoral y de la evangelización.

En segundo lugar, no puede considerarse una teología regional o sectorial (doctrinal o geográficamente), pues es una reflexión que abarca y afecta a todo el misterio cristiano.

Cabría advertir, como último dato, que se ha puesto de manifiesto también su relevancia en el campo de la espiritualidad y que con ella se ha recuperado en nuestros días el sentido teológico del martirio. Esta teología no acepta, por tanto, el ser relegada al campo meramente pastoral, pues se adentra también en la vida espiritual cristiana.

42. C. Floristán, Ver-juzgar-actuar, en Nuevo Diccionario de Pastoral, Paulinas, Madrid 1990, 1567.

43. E. Dussel, Dominación-liberación. Un discurso teológico distinto: Concilium 96 (1974) 328-352; P. Richard, Teología de la liberación: un aposte crítico a la teología europea: Páginas 3 (1976); Id., Teología de la liberación, en Mysterium salutis I, 201-222; M.-D. Chenu, La autoridad del evangelio y la teología, en Varios, Vida y reflexión. Apuntes de la teología de la liberación al pensamiento teológico actual, Lima 1983. 
Es, en definitiva, una teología integral, global, ya que se ocupa de la totalidad de los temas teológicos y en todos ellos deja su impronta; no es una teología genérica o abstracta, ni sectorial ni parcial, pues se ocupa del íntegro «depósito de la fe».

Advirtamos, no obstante, que si no es objetivamente particular, sí lo es formalmente en cuanto que abarca la globalidad de la fe de una forma peculiar que la diferencia de otras teologías cristianas, con relación a las cuales supone una "complementariedad crítica» ${ }^{44}$. Dicho en síntesis: es una teología integrada e integradora ${ }^{45}$.

\section{ONDA EXPANSIVA DEL MÉTODO «VER-JUZGAR-ACTUAR»}

La Teología de la liberación ha calado hondo en la teología postconciliar Una de las señas de su vitalidad es el influjo en el resto de la teología ¿El método teológico de América Latina para toda la Iglesia? Este método no puede erigirse como maestro al que hay que imitar, pero a partir de la Asamblea de Medellín, se inicia algo importante ${ }^{46}$.

En este apartado, vamos a centrarnos principalmente en la metodología de la Teología de la liberación latinoamericana y, más concreto, en el método ver-juzgar-actuar desarrollado y popularizado por ella. Ya hemos hecho referencia a este método usado incluso en documentos del magisterio de la Iglesia, en varias áreas de la vida cristiana y en obras señeras de teología postconciliar. Veámoslo con más detalle.

\section{a) Fecundidad de este método}

La Teología de la liberación y su correspondiente método, gestados en América Latina a partir del Vaticano II, han sido el referente principal para otras teologías (en plural) de la liberación, especialmente en África, en Asia y en determinados sectores sociológicos (negros, indígenas, los «sin tierra», los «sin papeles», mujer...). Pero ese referente no ha sido una simple copia, sino que cada teología de la liberación tiene su peculiar perfil, personalidad y especificidad. Estas teologías no son simples sucursales respecto de la casa central. A partir de las señas de identidad de cada pueblo, estas «teologías de la liberación» no se estructuran miméticamente en conformidad con la teología latinoamericana, sino que son elaboradas

44. C. Boff, Epistemología y método de la teología de la liberación, 79-91.

45. Ibid., 94-95.

46. Documentos de Medellín, Mensaje final. 
desde su peculiar realidad y situación, con claras señas de identidad, y tratan de responder a los desafíos de su entorno.

Si para la «Teología de la liberación» de América Latina el correlato de la liberación era la opresión y la dependencia de las que había que liberarse, con el pobre como síntesis y protagonista central, puede haber, y de hecho ha habido, otros muchos correlatos, a saber: la opresión de tipo racial (negritud), de tipo étnico (indígenas), de tipo sexual (mujer), por la condición social (anciano, niño, joven), de tipo político (emigrantes, desplazados, exiliados), de tipo legal (los «sin papeles», desconocimiento de los derechos humanos). Existe, por tanto, una vasta concepción del «pobre» ${ }^{47}$ y de opresión social, de modo que hay que ampliar el concepto de pobre tanto atendiendo a la Biblia como a la sociología humana y política.

Nos encontramos, por tanto, con que hay pluralidad de «teologías de la liberación»; pero más importante aún es que en todas resulta válido el método ver-juzgar-actuar. Esta constatación teológica nos remite necesariamente a la «Teología de la liberación» de América Latina, como realización teológica propulsora de la que son históricamente deudoras otras teologías. Se ha escrito que la Teología de la liberación «es estudiada en todo el mundo, también en sus puntos débiles. Pero ¿qué teólogo no se ha equivocado alguna vez?» ${ }^{48}$.

Se está volviendo al ya clásico método ver-juzgar-actuar. Se estudia su desarrollo, se estudian los contextos contemporáneos y su correspondiente situación de opresión y dependencia..., todo lo cual significa un desafío para la teología. Nuevas sensibilidades culturales y religiosas irrumpen en el escenario teológico. La aparición de la diferente óptica asiática o africana, la irrupción de la mujer y del movimiento feminista, los fenómenos de emigración y de desplazamientos masivos, el discurso postmoderno y postcolonial entre otros muchos factores, han introducido nuevos elementos en el esquema clásico del método ver-juzgar-actuar, que, no obstante,

47. «Hoy hay que explorar en particular los nuevos rostros de los pobres en diferentes contextos, en esta era de la globalización... Este orden económico globalizado afecta a las vidas de los pobres, a las comunidades eclesiales y al mundo en que hacemos teología» (Editorial: Concilium 361 [2015] 10, monográfico «La globalización y la Iglesia de los pobres»; J. Mo Sung, El pobre después de la teología de la liberación: Concilium 361 (2015) 439-450.

48. E. Schillebeeckx, La opción equivocada: Misión abierta 1 (1985) 102. Sobre la proyección de la «Teología de la liberación latinoamericana» en el exterior, cf. J. Ramos Regidor, Europa y las teologías de la liberación: Iglesia viva 116-117 (1985); J. J. Tamayo-Acosta, Recepción en Europa de la teología de la liberación, en Mysterium liberationis I, 57-77; J. B. Metz, Un nuevo modo de hacer teología. Tres tesis, en Varios, Vida y reflexión, Lima 1983; P. Richard, Teología de la liberación: un aporte crítico a la teología europea: Páginas 3 (1976); C. Floristán - J. J. Tamayo, El Vaticano II, veinte años después, Madrid 1985, 429-463. 
permanece en su estructura ${ }^{49}$. Pero, al margen de estos nuevos factores y de los cambios que conllevan, parece necesario «recuperar la intuición de la primera generación de los teólogos de la liberación $»^{50}$, por ejemplo, de Gustavo Gutiérrez ${ }^{51}$. El objetivo de la revisión actual del método «no es recuperar nostálgicamente cierto universo orgánico y pre-moderno, sino desafiarnos a afrontar directamente las concretas situaciones difíciles que encontramos en los actuales contextos globales» ${ }^{52}$.

\section{b) Otras teologías de la liberación: legitimidad y peculiaridad}

Hay otras teologías que se acercan al método ver-juzgar-actuar de forma un tanto peculiar, sin ser copia de la clásica teología de la liberación.

Comencemos con unas observaciones preliminares. No todos vemos las cosas de la misma manera, es necesaria la perspectiva del conocimiento. Las cosas son siempre peculiares cuando se ven desde un determinado punto de vista, luego cualquier visión es necesariamente parcial. Es una condición permanente que acompaña al conocimiento humano y, por tanto, también al teológico. Conocemos la realidad desde una situación no escogida, sino que nos viene dada por el contexto que nos envuelve, situación "en la que nacimos y nos desarrollamos» (P. Ricoeur). La visión de la realidad no es para todos igual, así como las consecuencias concretas que para cada uno se derivan de esa realidad. Además, todo conocimiento responde a unos intereses, no hay un conocimiento ni una visión neutral de la situación.

Al ser esto así, es legítimo el «ver» la realidad que lleva a cabo la teología y la pastoral, que hacen su análisis desde una perspectiva determinada a la luz del Evangelio para transformar la realidad que tienen delante.

Un teólogo pastoralista actual propone seis preguntas para el «ver» en el ámbito pastoral: dónde, cuándo, quiénes, qué, cómo y por qué ${ }^{53}$. En una palabra, el «ver» analiza la realidad, capta los acontecimientos, examina los «signos de los tiempos» y percibe los hechos de vida ${ }^{54}$. Para lograr todo lo relacionado con el «ver» es de indiscutible utilidad para el teólogo recurrir a los instrumentos de las ciencias sociales.

49. R. Biord Castillo, Ponderación teológica del método ver-juzgar-actuar, nota 16.

50. Ibid., 36.

51. G. Gutiérrez, Teología de la liberación, Sígueme, Salamanca 1971.

52. R. Biord Castillo, Ponderación teológica del método ver-juzgar-actuar, 37.

53. C. Floristán, Ver-juzgar-actuar, 1565.

54. Id., Teología práctica, 390. 
Las reflexiones precedentes preparan el ánimo para entender lo que sigue, es decir, cómo a lo largo de la historia se ha reflexionado en teología con un método equivalente a nuestro ver-juzgar-actuar, si bien, lógicamente, con una formulación muy distinta de la actual.

\section{DIVERSIDAD DE VERSIONES DEL MÉTODO EN LA HISTORIA}

\section{a) Planteamiento}

El método teológico ver-juzgar-actuar es de naturaleza inductiva e histórica. Hemos visto que se estructura en tres momentos: a) el hombre que percibe la realidad en que vive, que la analiza científicamente; b) Dios que entabla un diálogo con el hombre sobre esa realidad, Dios que habla y se posiciona ante la realidad humana e histórica; c) culmina el proceso el hombre con una respuesta que le compromete, con una incorporación activa al diseño del plan salvador de Dios.

Estos tres momentos no son senderos diversos o autónomos, ni discurren de modo paralelo, sino que son etapas de un único camino o proceso vital del pensar creyente; son tres funciones de la teología, que es una unidad viva de búsqueda y comprensión. Pues bien, esto es lo que encontramos en el campo de la teología, expresado de formas muy diversas, pero coincidiendo en el fondo de la cuestión, en el método.

Vamos a ofrecer una especie de síntesis del método ver-juzgar-actuar, diversas ópticas que nos muestran su presencia en la historia mucho antes de ser formalmente formulado tal principio. Advertimos que en el fondo se respetan los tres clásicos momentos del método: el momento cultural-socio-político del «ver»; el momento hermenéutico-teológico del «juzgar», y el momento práxico del compromiso creyente o el «actuar».

Hagamos aquí una observación: estos tres momentos tienen perfil diverso en cada época histórica, no son simples bloques que se transmiten mecánicamente sin alteración; justamente ese perfil diverso es lo que va a justificar la síntesis, o sea, las coincidencias fundamentales de proyectos teológicos de épocas distintas. Iniciemos el recuento al hilo de la historia.

\section{b) Concilio Vaticano I}

Puede extrañar a más de uno que nos remontemos al concilio Vaticano I para hablar del método ver-juzgar-actuar. Pero, a su modo, con su propia terminología, vemos que responde a lo esencial de la estructura de nuestro método (DH 3016). 
En efecto, contiene lo que podemos llamar «compañía del existir humano»; es el conocimiento del misterio por analogía de lo que el hombre puede conocer naturalmente. Se da, en segundo lugar, lo que podemos llamar «memoria de la Palabra y fidelidad a la misma», o sea, conocimiento del misterio "por la conexión de los misterios entre sí» en el interior del mundo de la revelación y de la fe. Y hallamos, en tercer lugar, lo que puede llamarse «profecía del futuro», que en el lenguaje del Concilio es conocimiento del misterio por la «conexión con el fin último del hombre».

Por consiguiente, nos encontramos con los tres momentos constitutivos del método ver-juzgar-actuar, pero en un lenguaje y una sensibilidad teológica muy distinta de la actual.

\section{c) Concilio Vaticano II: "Gaudium et spes» y "Optatam totius»}

El Vaticano II no usa la terminología hoy clásica de ver-juzgar-actuar, pero su método teológico gravita sobre esta base. Podemos constatar esto especialmente en dos documentos emblemáticos para nuestro tema: la constitución pastoral Gaudium et spes y el decreto Optatam totius.

Gaudium et spes. El primer momento del método se puede expresar condensadamente en la fórmula «signos de los tiempos» (GS 4; 11; 44), o sea, esos acontecimientos históricos y sociales con especial significado humano al alcance de nuestra observación natural y científica ${ }^{55}$; aquí se expresa con claridad el «ver». El segundo momento es lo que tipifica al documento conciliar, elevándolo al rango teológico, más allá del nivel puramente histórico o sociológico, y que el Vaticano II expresa con la frase «a la luz del Evangelio»; los acontecimientos «hablan» al creyente de la voluntad de Dios, y la manifiestan para cada época; se trata del momento hermenéutico, decisivo y diferenciador, el específico del trabajo teológico, el «juzgar» ${ }^{56}$. El tercer momento apunta a la intencionalidad del Concilio, claramente expresada a lo largo del documento Gaudium et spes desde su primer párrafo: «Para hacer posible un mundo más cristiano». Así se nos convoca a una acción comprometida y transformadora, línea que se despliega a lo largo de todo el documento como «actuar» (cf. en especial GS 46).

Optatam totius, 16. La formación de los sacerdotes prácticamente reproduce el esquema visto en Gaudium et spes. En efecto, se insiste en la necesidad de "escuchar y sintonizar con el mundo en que vivimos»,

55. Para este primer momento, sobre todo, GS 1.22.

56. Para este asunto, sobre todo GS 23-45 y 91-92. 
se enfatiza la necesidad del diálogo con el pensamiento actual para restablecer con el mundo presente el puente que se había roto («ver»). La formación propuesta por la Iglesia «retorna a las bases bíblicas y de los grandes testimonios de la tradición cristiana»; se trata de captar el misterio de la fe en el hoy, de reavivar la revelación para que siga siendo el faro de la existencia creyente («juzgar»). Por último, se pretende «conjugar mundo y fe», superando la dicotomía tantas veces lamentada de fe y vida; es ahora el «lenguaje de la vida» el que debe imperar, y es el momento más propicio para el testimonio cristiano y el compromiso con la fe que se profesa («actuar»).

\section{d) Magisterio más reciente de la Iglesia}

En aras de la brevedad, nos limitamos a una referencia concreta del papa Pablo VI en la encíclica Octogessima adveniens (1971). Estas son sus palabras, que marcan nítidamente los tres momentos clásicos del método ver-juzgar-actuar sin usar dicha terminología: «Incumbe a las comunidades cristianas: a) analizar con objetividad la situación propia de su país; b) procurar esclarecerla mediante la luz de la palabra inalterable del evangelio; c) discernir las opciones y los compromisos (en cursiva) que conviene asumir para realizar las transformaciones sociales ${ }^{57}$. Sin duda es un texto clarividente.

\section{e) Atentos al pensamiento actual}

Tratando de acoger y resumir en unas líneas el pensamiento actual, sobre todo el teológico manifestado a través de cauces diversos, podemos señalar estos fenómenos: a) Conciencia actual de valorar el momento que vivimos; b) Adviento, expectativa ante el gran don de Dios que sale de sí y va al encuentro del hombre, respondiendo a las aspiraciones humanas con gestos salvíficos («mirabilia Dei»), que se constituyen en referencia absoluta; es el incomparable acontecimiento pascual. c) Presencia activa del hombre, fundada en la alianza, que se da entre el éxodo humano y el adviento divino; encuentro fecundo y siempre nuevo: Dios presente y el hombre peregrino hacen el camino conjuntamente de la muerte a la vida.

57. Pablo VI, encíclica apostólica Octogessima adveniens, 4; 42; 48; los subrayados son nuestros. 


\section{f) Una propuesta teológica actual: Bruno Forte}

En su obra La teología como compañía, memoria y profecía. Introducción al sentido y al método de la teología como historia ${ }^{58}$, el teólogo italiano reflexiona sobre cada uno de los tres momentos.

Compañía. Implica el diálogo con los retos que plantea el contexto humano-cultural. Entraña solidaridad con el mundo, que es «lugar del Evangelio». Significa situarse en la brecha de la historia, buscando con el hombre que busca.

Memoria. Mirada clarificadora a las fuentes cristianas, sobre todo a la fontalidad del Nuevo Testamento, pero también a los Padres y a la gran tradición teológica, que han roturado un camino que da acceso a Dios.

Profecía. Es la mirada hacia adelante. Bajo la guía del Espíritu, se hace una síntesis de compañía y memoria. Ello significa apertura al futuro, a nuevas posibilidades contenidas en la promesa divina. Estamos «en camino», no está dicho ni hecho todo.

\section{g) Aplicación del método a la actual teología del diaconado}

La teología del diaconado postconciliar, en especial la del diaconado permanente, nos ofrece una versión peculiar del método ver-juzgar-actuar ${ }^{59}$.

En la propuesta de Klaus Keisseling, se expone paralelamente la actuación de las facultades humanas cabeza, corazón y manos, articuladas con los tres momentos de "ver», «juzgar» y «actuar», es decir, se articula la totalidad del creyente. Veámoslo con la terminología empleada por el autor.

1. Ver. Es la «mística de los ojos abiertos» (J. B. Metz). Corresponde a lo que llamamos «análisis de la situación» en nuestro método, es el necesario inicio del proceso, es la situación captada por nuestra retina, en nuestra mente-cabeza. Nos situamos en el horizonte universal, atentos al acontecer de nuestro ámbito socio-eclesial.

Se nos remite a la sintonía con la realidad del sufrimiento y de cualquier carencia y necesidad del hombre; cerrarse al servicio o diaconía que se puede prestar es clausurarse en sí mismo, es permitir que fracase y muera lo que tiene derecho a vivir; hay que luchar para que viva.

58. Publicada en Sígueme, Salamanca 1990.

59. K. Keisseling, en Diakonia Christi 45 (2010). Helf 1-2 presenta un sorprendente paralelismo con nuestro método, recurriendo a una terminología propia y sugestiva. El autor de este trabajo es el Presidente del Centro Internacional del Diaconado. Vamos a ofrecer su propuesta, que resumimos en el folleto Diaconado permanente. Representación sacramental de Cristo Siervo, Colegio Diaconal de la Arquidiócesis de Maracaibo, Maracaibo 2013, 65-70. 
La «mística de los ojos abiertos» remite al creyente a un Dios misericordioso que se compadeció de su pueblo sufriente y que ahora se hace «presente y operante» en el hombre que ejerce la diaconía, el que se abre a la miseria de los demás, el que se siente movido por la compasión, a zaga de Yahvé en el Antiguo Testamento y de Jesús en el Nuevo: «Siento compasión de...». Estas palabras nos harán sentir la obligación de percibir la necesidad ajena, atentos a los «signos de los tiempos» en cada lugar del mundo. Si tenemos los «ojos abiertos», descubriremos dónde y cómo percibir el padecer humano y, consiguientemente, fomentar la compasión y poner en marcha la misericordia.

2. Juzgar. Es la «mística del corazón amplio». En este segundo paso del proceso, entran en juego el corazón y la fe bajo la autoridad de la Palabra de Dios, dispuestos a acoger todas las luces y aportes procedentes de Dios y de la diaconía eclesial.

A partir de la «mística del corazón amplio», adquiere una nueva significación y urgencia lo percibido con la «mística de los ojos abiertos», introduciéndonos en otro horizonte. Ahora nos acercamos como creyentes y cordialmente, de manera diaconal, a lo ajeno (dolor, miseria, necesidad, penuria...) para verlo desde el punto de vista de la Palabra de Dios y de la fe. Entonces resulta que lo ajeno no puede resultarnos extraño; si nos abrimos al misterio de Dios (a su Palabra) captamos lo que significa «corazón amplio». La trayectoria y ejemplo de Jesús de Nazaret resulta ser la mejor pedagogía.

Precisamente el Concilio Vaticano II se ocupa detenidamente del diaconado permanente en el documento más directamente misionero, dedicado a los alejados (AG 1); de la solidaridad con el mundo que espera ser evangelizado se sigue la diaconía, conscientes de que Dios quiere ser encontrado en los más necesitados. Recordemos: "Yo era un extraño, y me hospedasteis» (Mt 25, 35); y lo contrario (Mt 25, 43s), Jesús nos dice que lo encontraremos ahí, en «sus más pequeños hermanos». En lo ajeno y lejano Dios se hace cercano a los hombres.

Hay que compartir con todos, sin restricción: «Paz a los de lejos y a los de cerca» (Is 57, 19); el mejor ejemplo lo hallamos de nuevo en Jesús, que se dedicó a todos sin dejarse acaparar por nadie, aunque, eso sí, en la opción por los pobres hallaremos su contraseña (Lc 4, 18; Mt 11, 5). Aquí se encuentra la clave de su paradójico universalismo, puesto que al preferir a los más necesitados, nadie queda excluido, se salva a la humanidad desde abajo, desde las raíces. Todo ello a contrapelo de los 
criterios del mundo y de la sociedad, de las fuerzas del anti-reino. Nos estamos moviendo en el nivel de la fe y del corazón, en el ámbito de lo más genuino de la «buena nueva», solo desde la cual se puede entender al profeta: «Mis planes no son vuestros planes, mis caminos no son vuestros caminos» (Is 55,8$)$.

3. Actuar. La «mística de las manos dispuestas a la acción». No basta con la cabeza («ver») ni con el corazón («juzgar»), deben intervenir también las manos («actuar»), hacer que surja del contacto con la realidad un compromiso traducido en acción. La teología cristiana tiene que conjuntar la teoría y la práctica, la ortodoxia y la ortopraxis.

El vivir solidario. El «Dios solidario» con el hombre se muestra en el «Dios salvador y liberador», alcanzando la cima de la solidaridad en la encarnación de su Hijo, el «hombre para los demás». Dios realiza la salvación no mediante un simple decreto divino, sino mediante una cadena de intervenciones en la historia, acciones que tejen la historia de la salvación. Este deberá ser el trasfondo bíblico de nuestro compromiso (Jn 3, 16-17; 4 , 9; 5, 17.30; 6, 39; 9, 30; 10, 28.37; 17, 6.9.21). En estos testimonios del cuarto evangelio se delinea claramente que Jesús bajó a la arena de la vida y entró en una dinámica a favor del hombre. Pablo, por su parte, insistirá en el «por nosotros» (Flp 2, 7; Rm 4, 25). Jesús rebasó la perspectiva de mero espectador y «compartió la suerte de los pecadores, cargando con el pecado de muchos» (Is 53, 12).

El amor hecho servicio, corazón que moviliza las manos, diaconía efectiva, la de las «manos dispuestas a la acción». Hay que actuar en momentos y en asuntos en que el otro no puede hacerlo, o no sabe hacerlo, o no cree en el resultado positivo del compromiso. Precisamente el diácono cristiano nos recuerda a todos que hay que vivir de manera transformadora y proactiva de cara al mundo, en favor de los demás. Los que viven sin esperanza alguna, los que se debaten en las tinieblas necesitan personas-luz que les abran camino y aporten sentido, alguien que haga renacer en ellos la ilusión.

El trasfondo cristiano de esta actitud servicial será en todo momento Cristo, el «diácono» que vino a servir y no a ser servido (Mt 20,28), el que va delante en el programa de acción evangélica (Jn 13, 5.14-15). «Actuar», mística de las manos, entrega y compromiso como reza el himno litúrgico: «Tarea y aventura entregarme del todo, ofrecer lo que llevo, gozo y misericordia». 


\section{AVENTURANDO UNA SÍNTESIS}

a) Al hilo de las virtudes teologales

A continuación, vamos a presentar una visión de conjunto, en clave teológica y a partir de las virtudes teologales, de lo expuesto sobre el método teológico «ver-juzgar-actuar».

Ver. Conciencia del presente. «Docta caritas». Hay que comenzar por la solidaridad amorosa con el hombre histórica y culturalmente situado que es el realmente existente. Es el amor cristiano hecho reflexión o análisis, y hecho palabra sin evasiones ni miedos. Es ese amor concreto, cercano, encarnado para el servicio del hombre, un «amor con ojos» que levanta acta de la realidad. «Ubi amor, ibi oculus».

Juzgar. Memoria del plan salvífico de Dios. «Docta fides». Consiste en actuar una memoria viva de la Palabra de Dios, que alimenta una fe vivida, pensada y comunicada. Se trata de la actualización de la promesa recibida "ex auditu», contenida en las fuentes de la revelación, naciendo por tanto de las mismas raíces cristianas: Escritura, Tradición, Liturgia, Padres, Historia de la Iglesia y de la fe. Aún más, se da una aceptación gozosa y agradecida de este gran y rico patrimonio cristiano, porque Dios peregrina con el hombre en el tiempo.

Actuar. Apertura al futuro. "Docta spes». Es un pensamiento anticipador y alimentador de esperanza, es la seguridad que da la apertura constante al don de Dios que nos quiere colaboradores en su obra salvadora. Se trata, pues, de una esperanza histórica y, por tanto, siempre «en camino» hacia la vida y la verdad. Es el anhelo nunca satisfecho, deseoso siempre de una felicidad fugitiva; y, al mismo tiempo, es la convicción de que la acción y el compromiso cristiano da frutos. Como reza el hombre peregrino con el himno litúrgico, «lo bueno y noble perdura eternizado en la dicha» Irrumpe lo nuevo, lo sorpresivo (Ap 21, 1-2). Se cumple la profecía (Is 42, 9; 43, 18-19; 65, 17s).

\section{b) Validez del método}

Hemos visto el modelo teológico ver-juzgar-actuar desde varias vertientes. Hemos podido comprobar los valores que encierra en el amplio y variopinto arco de la teología, sobre todo si tenemos en cuenta que se ocupa de nuestro pasado inmediato existencial, de nuestro presente más actual y nos abre hacia el futuro, con la Palabra de Dios como luz y guía; se acierta así a conjugar las «tres edades del tiempo», el ayer, el hoy y 
el mañana. $Y$ hemos podido constatar la presencia del método al menos desde el Vaticano I hasta la teología contemporánea, pasando por el relanzamiento decisivo del Concilio Vaticano II.

¿Por qué ver-juzgar-actuar es un método pastoral adecuado hoy, como corrobora su seguimiento en todas partes? Veamos algunas razones:

- Porque analiza y valora la importancia de la praxis concreta, al alcance de todo creyente, con la notable dosis de realismo que ello comporta.

- Porque está anclado en la realidad más cotidiana, conocida y vivida, y tantas veces padecida o meramente soportada.

- Porque tiende el anhelado puente entre fe y vida.

- Porque discierne la situación que se vive a la luz del proyecto de Dios.

- Porque enriquece y ensancha la acción humano-creyente, sobrepasando la tiranía de la práctica o de la simple productividad.

Podemos, por tanto, deducir que este método inductivo: ver-juzgar-actuar, es válido y goza de reconocida actualidad.

\section{c) Límites del método}

Los métodos son instrumentos, es decir, nos sirven para hacer algo o conseguir un fin. Todos los métodos son tan sólo caminos.

El método ver-juzgar-actuar puede ser bien usado o mal usado, logrando su objetivo o fracasando en el intento. Pero esto no depende del método, sino de los usuarios. No hay recetas seguras y prefijadas que den los mismos resultados positivos en todo lugar y de igual manera. El método ver-juzgar-actuar no actúa en sí mecánicamente y siempre con garantía de éxito; se puede "ver», «juzgar» y «actuar» erróneamente. Por ello, no debe absolutizarse este método, ni se le debe considerar el único camino válido para hacer teología.

La lección nos viene del Evangelio, que nos enseña a fijar la atención no sólo en la semilla que sembramos, sino también en el terreno donde se siembra; la simiente puede ser indiscutiblemente buena, pero hay que tener en cuenta la situación a la que se aplica.

«Ver», «juzgar»y «actuar» no son elementos autónomos e independientes, sino que forman un bloque, se complementan entre sí, son correlativos y no meramente sucesivos, forman un gran relato. La simple yuxtaposición de partes en este método sería fatal. El verdadero diagnóstico sobre la situación que sometemos a estudio se obtiene mediante la articulación interna de los diversos pasos o elementos constitutivos del método. 
Un peligro que puede acechar a este método es el «inmediatismo pastoral», que supone con frecuencia un pasar por alto otros elementos, atendiendo sobre todo al "actuar». Otro peligro al acecho es el «activismo» (hacer, hacer, hacer...); no siempre lo urgente es lo más importante y lo más práctico.

En conclusión, el fruto completo que cabe esperar de este método únicamente se obtendrá teniendo en cuenta y respetando su naturaleza y el peso teológico específico de cada momento: ver, juzgar, actuar, evaluar y celebrar. 